This is the author's final, peer-reviewed manuscript as accepted for publication. The publisher-formatted version may be available through the publisher's web site or your institution's library.

\title{
Increased growing temperature reduces content of polyunsaturated fatty acids in four oilseed crops
}

L. R. Schulte, T. Ballard, T. Samarakoon, L. Yao, P. Vadlani, S. Staggenborg, M. Rezac

\section{How to cite this manuscript}

If you make reference to this version of the manuscript, use the following information:

Schulte, L. R., Ballard, T., Samarakoon, T., Yao, L., Vadlani, P., Staggenborg, S., \& Rezac, M. (2013). Increased growing temperature reduces content of polyunsaturated fatty acids in four oilseed crops. Retrieved from http://krex.ksu.edu

\section{Published Version Information}

Citation: Schulte, L. R., Ballard, T., Samarakoon, T., Yao, L., Vadlani, P., Staggenborg, S., \& Rezac, M. (2013). Increased growing temperature reduces content of polyunsaturated fatty acids in four oilseed crops. Industrial Crops and Products, 51, 212-219.

Copyright: @ 2013 Published by Elsevier B.V.

Digital Object Identifier (DOI): doi:10.1016/j.indcrop.2013.08.075

Publisher's Link: http://www.sciencedirect.com/science/article/pii/S0926669013004950

This item was retrieved from the K-State Research Exchange (K-REx), the institutional repository of Kansas State University. K-REx is available at http://krex.ksu.edu 
1 Increased Growing Temperature Reduces Content of Polyunsaturated Fatty Acids in Four

2 Oilseed Crops

3 Authors: Schulte, L.R. ${ }^{\mathrm{a}}$, Ballard, T. ${ }^{\mathrm{b}, 1}$, Samarakoon, T. ${ }^{\mathrm{c}, 2}$, Yao, L. ${ }^{\mathrm{c}}$, Vadlani, P. ${ }^{\mathrm{d}}$,

4 Staggenborg, S. ${ }^{\mathrm{e}, 3}$, Rezac, $\mathrm{M}^{\mathrm{f}}{ }^{\mathrm{*}}$

$5{ }^{\mathrm{a}}$ IGERT in biorefining, Department of Chemical Engineering, Kansas State University,

6 Manhattan, KS 66506, USA

7 bIGERT in biorefining, Department of Agronomy, Kansas State University, Manhattan,

8 KS 66506, USA

9 'Kansas Lipidomics Research Center, Kansas State University, Manhattan, KS 66506,

10 USA

11 Department of Grain Science and Industry, Kansas State University, Manhattan, KS

12 66506, USA

13 ' Department of Agronomy, Kansas State University, Manhattan, KS 66506, USA

$14{ }^{\mathrm{f}}$ Department of Chemical Engineering, Kansas State University, Manhattan, KS 66506,

15 USA

$16{ }^{1}$ Present address: Okeelanta Corp Agricultural Research, 21250 US Highway 27, South

17 Bay, FL, 33493, USA

$18{ }^{2}$ Present address: Department of Chemistry, Kansas State University, Manhattan, KS

19 66506, USA

$20{ }^{3}$ Present address: Chromatin, 403 South Monroe, New Deal, TX 79350, USA

21 Received__April 2013. *Corresponding author (+1 7855325584, rezac@ksu.edu). List of Abbreviations: Oleic acid = C18:1; Linoleic acid = C18:2; Linolenic acid $=$ C18:3; Gas Chromatography or Gas Chromatograph = GC; Flame Ionization Detector = FID 


\section{Abstract}

23 Environmental temperature directly influences the lipid profile produced by oilseeds. If

24 growing temperatures increase, as is predicted by current models, the precise profile of

25 lipids produced are likely to change. This paper develops models to predict lipid profiles

26 as a function of growing temperature. Data relating to lipid profiles of soybean (Glycine

27 max), spring canola (Brassica napus), spring camelina (Camelina sativa), and sunflower

28 (Helianthus annuus) were gathered from the literature and evaluated to examine the

29 influence of temperature on relative production of oleic, linoleic, and linolenic acid. For

30 each crop, a set of linear regressions was used to correlate temperature during the grain

31 fill, defined as 30 days before harvest, with the molar percentages of oleic, linoleic, and

32 linolenic acid present. An increase in temperature from 10 to $40^{\circ} \mathrm{C}$ resulted in an increase

33 in the production of oleic acid and a decrease in the production of linoleic and linolenic

34 acid in soybeans, canola, and sunflowers. Over the range of data available, the lipid

35 profile of camelina was temperature insensitive. To test the validity of the correlations,

36 the four crops were grown in a field study in Manhattan, Kansas simultaneously, in the

37 same environment, in 2011. The correlations accurately predicted the field data for

38 soybean, canola, and camelina but not for sunflower. The correlation for sunflower

39 under-predicted the molar amount of oleic acid and over-predicted the molar amount of

40 linoleic acid. This study indicates increasing growing temperatures from 10 to $40^{\circ} \mathrm{C}$ will

41 result in more monounsaturated oils and less polyunsaturated oils in soybean, canola, and

42 sunflower.

43 Keywords: Fatty acid profile; unsaturated oils; Glycine max; Brassica napus; Camelina

44 sativa; Helianthus annuus 


\section{Introduction}

$46 \quad$ Plant lipids are important because of their use as food, fuel, and chemicals. Lipids

47 also have uses as starting materials for surfactants, lubricants, epoxides, coatings, inks,

48 polymers, and other products in the chemical industry (Metzger and Bornscheuer, 2006).

49 The lipid profile of a seed can affect its end use. In oils for human consumption, linoleic

50 acid is valued for its health benefits but linolenic acid results in oil having a poor

51 oxidative stability and shortened shelf life (Singh et al., 2010). For biodiesel production,

52 it is desirable to have a lipid profile that is highly saturated to minimize oxidation of

53 double bonds because oxidized methyl esters can form polymers that plug fuel filters and

54 damage engine performance (Monyem and Gerpen, 2001). Specific lipid profiles also

55 influences reactivity. Multiply unsaturated lipids have been shown to have a higher

56 reactivity than monounsaturated species (Singh et al., 2009, 2011).

57 Fatty acid profiles are influenced by plant type, genotype, temperature,

58 environmental conditions, and agricultural practices (Harris et al., 1978). Several studies

59 have examined the effect of temperature on fatty acid composition of the grain (Canvin,

60 1965; Aksouh et al., 2001; Ren et al., 2009). Many studies examining how temperature

61 influenced the resultant seed lipid profile were performed in greenhouses but greenhouses

62 can only approximate growing conditions in the field and cannot give a complete picture

63 of how crops will respond to different temperatures (Canvin, 1965; Aksouh et al., 2001;

64 Ren et al., 2009). Conversely, data from field studies only encompass a relatively narrow

65 temperature range (Nagao and Yamazaki, 1983; Putnam et al., 1991; Gugel and Falk,

66 2006; Gao et al., 2009). Most studies found that as temperatures rise, the percentage of

67 polyunsaturated lipids, linoleic (C18:2) and linolenic (C18:3) in particular, decreases 
68 while the percentage of oleic acid (C18:1) increases. Yet each of the prior studies is

69 limited in scope, typically including only one crop grown in a handful of locations,

70 resulting in growing conditions across a limited temperature range. The general

71 consensus from these studies is that growing temperature and genotype are the main

72 factors contributing to the large variation within a crop’s lipid profile (Lajara et al., 73 1990).

74 In the current work, the literature was reviewed to determine if temperature is the 75 single dominant factor influencing lipid composition. In this paper, 25 studies of oil

76 profiles for crops grown in fields and greenhouses were compiled with temperatures

77 ranging between 10 and $40^{\circ} \mathrm{C}$ to provide a more complete understanding of how lipid

78 profiles are affected by temperature. Temperature during the grain fill, defined as 30 days

79 before harvest, was correlated with the percentage of major lipids contained in soybean,

80 canola, camelina and sunflower. Then the oilseed crops were grown and the lipid profile

81 of their seeds was determined and compared to the literature to demonstrate the validity

82 of the determined correlations.

83 Oilseed crops were chosen for their ability to grow in the Midwest and their

84 potential for use as a feedstock for production of biodiesel or other biochemicals.

85 Soybean (Glycine max) is the most valuable oilseed crop in the United States in terms of 86 production and economic value as it accounts for over 90 percent of U.S. production of

87 biodiesel and is a dominant food product (Gao et al., 2009). Over 50 million metric tons

88 of canola (Brassica napus) is produced annually, making it the world's third most

89 important oilseed crop behind palm and soybean (Downey, 1990). Camelina (Camelina

90 sativa) is a relatively new oilseed crop that because of its low agricultural inputs and 
91 ability to grow on marginal lands, could play an important role in food and fuel

92 production in the future (Budin et al., 1995). Sunflower (Helianthus annuus) is one of the

93 five largest oilseed crops in the world with over 1.5 million acres of sunflower planted in

94 the US in 2011 (“Economic Research Service, USDA. 'Table 20: Sunflowerseed:

95 Acreage planted, harvested, yield, production and value, U.S., 1980-2011',” n.d.).

96 Compared to previous multi-crop studies on seed oil compositions, the current study is

97 distinct in that it includes camelina with the traditional crops (Werteker et al., 2010).

98 Our objectives were to gather literature data on lipid profiles over a large range of

99 growing temperatures and correlate the temperature during the grain fill to the molar

100 amount of lipid contained in the seeds. The correlations were compared to field studies to

101 demonstrate their validity.

102 2. Materials and methods

\section{2.1. Collecting lipid profiles from literature}

104 For field studies, literature was included in this review if the study included the

105 location where the crops were grown and harvest date (or sufficient data with which to

106 make a reasonable estimate of the date of harvest). If only the planting date was given,

107 the harvesting date was assumed to be the average of the recommended days to allow the

108 plant to grow in the field. For soybean the assumed harvest date was 100 days after

109 planting while for the short season crops, canola, camelina, and sunflower, the assumed

110 harvest date was 92 days after planting. The mean monthly maximum temperature for

111 each location was found in the National Oceanic and Atmospheric Administration's

112 National Climatic Data Center. If the grain filling days spanned two months, the average

113 mean maximum temperature of that period was calculated, accounting for the days of 
114 grain filling in each month. For greenhouse studies, literature was included in this review

115 if temperature data was given. A list of the literature included in this review can be found 116 in Table 1.

117 Genotype has been documented to have an effect on the oilseed profile, so an

118 attempt was made to control for genotype in the collected literature. Only literature

119 studies with genotypes that matched the oilseed crops grown as validation studies were

120 used. Since few studies specifically articulated the genotype of the seeds, categorization

121 strategies were employed. Soybean cultivars have been considerably modified due to

122 genetic engineering and can have a wide variety of lipid profiles. Studies with more oleic

123 acid than linoleic acid were neglected because soybean in the field studies had twice as

124 much linoleic acid than oleic. The commercial canola evaluated is significantly different

125 from the wild Brassica napus varieties. By definition, canola is a Brassica napus hybrid

126 or variety with less than 5\% erucic acid, therefore Brassica napus oils with more than 5\%

127 erucic acid were neglected. Because it has not yet reached use maturity, camelina has

128 experienced limited genetic modifications, thus all data from the literature was included.

129 Commercially available sunflower hybrids have a wide variety of lipid profiles and are

130 classified by percentage of oleic acid. The sunflower hybrid used in this study was

131 classified as a mid-oleic line with oleic acid percentages between $55-75 \%$ and linoleic

132 acid percentages between 20-42\% (Grompone, 2005). Therefore, only literature studies

133 with these properties were included.

134 A linear regression was used to correlate the molar amount of each fatty acid as a

135 function of the mean maximum temperature during the grain fill. SAS software ("SAS

136 Version 8. SAS Institute Inc.,” 2006) was used to determine the parameter estimates for 
137 the linear regression. Residuals for each regression were plotted to determine that errors

138 were normally distributed and that the mean of the errors was zero.

139 2.2. Agricultural practices

140 A randomized complete block with four replications was used to plant maturity

1414.7 ('KS 4702’ Kansas St. Univ. Manhattan, KS) soybean, canola '1651h Clearfield’

142 (Cropland Genetics St. Paul, MN), camelina (Cheyenne, Blue Sun Biodiesel Golden,

143 CO), and sunflowers ‘559 CL, DMR, NS’ (Cropland Genetics St. Paul, MN), in

144 Manhattan, $\mathrm{KS}\left(98.3^{\circ} \mathrm{W}, 39.14^{\circ} \mathrm{N}\right)$ in 2011 . The soybean line was chosen because its

145 maturity matched the growing season. Cropland Genetics' canola and sunflower lines

146 were chosen for their herbicide resistance. The sunflower line is resistant to drought,

147 making it suitable for planting in central and western Kansas. The camelina line was

148 chosen because it is one of the few that is tailored for dryland farming and commercially

149 available. These crops were grown simultaneously in the same location to minimize

150 variations in weather patterns and soil types. Canola and camelina were planted 11 Mar.

1512011 and harvested 9 July 2011 and 29 June 2011 respectively. The soybean and a 95-

152 day relative maturity sunflower were planted as full season crops on 17 May 2011. The

153 sunflower crop was harvested at the end of August while the soybean crop was harvested

154 at the end of September. The non-legume crops received $112 \mathrm{~kg}^{*} \mathrm{ha}^{-1}$ of $(\mathrm{N})$ as urea

$155\left(\left(\mathrm{NH}_{2}\right)_{2} \mathrm{CO}\right) 15$ - 20 days after planting. The brassica crops received $22.4 \mathrm{~kg}^{*} \mathrm{ha}^{-1}$ of

156 sulfur (S) from gypsum $\left(\mathrm{CaSO}_{4}\left(\mathrm{H}_{2} \mathrm{O}\right)_{2}\right)$ simultaneously with the $\mathrm{N}$ broadcast application.

157 Following harvest, all crops were dried to 3\% moisture prior to oil extraction.

158 2.3. Extraction of lipids 
160 be found in Figure 1. The extraction and fatty acid synthesis procedure is a modification

161 from previous work by the same lab (Kim et al., 2013). The seeds were heated at $75^{\circ} \mathrm{C}$

162 for $15 \mathrm{~min}$ in $0.01 \mathrm{wt} \% \mathrm{BHT}$ in isopropanol to inactivate lipolytic enzymes. The mixture

163 was transferred to a homogenizer to crush the seeds. To separate the triglycerides from

164 the protein solids, $1.0 \mathrm{~mL}$ chloroform, $1.0 \mathrm{~mL}$ methanol and $0.8 \mathrm{~mL}$ of water were added.

165 The mixture was shaken for 30 seconds and centrifuged for 10 minutes at 10,000 rpm to

166 facilitate phase separation. The chloroform layer, containing the triglycerides, was

167 transferred to a separate vial and saved. The extraction was repeated three times, each

168 time adding more chloroform to the aqueous phase, with the triglyceride fraction

169 collected in a common vial. To remove any water that might have been carried over from

170 the extraction, $0.5 \mathrm{~mL}$ of $1 \mathrm{M} \mathrm{KCl}$ was added as a desiccant to the triglyceride solution

171 and the mixture was shaken and centrifuged. The upper aqueous layer was removed and

172 discarded. To remove any remaining proteins, $1.0 \mathrm{~mL}$ of water was added and the

173 mixture was shaken and centrifuged. The aqueous layer was discarded and the

174 triglyceride solution was then dried under nitrogen and redissolved in $1000 \mu \mathrm{L}$ of

175 chloroform.

$176 \quad$ For the synthesis of methyl esters, $25 \mu \mathrm{L}$ of the triglycerides solution and $50 \mu \mathrm{L}$

177 of internal standard, pentadecanoic acid in chloroform, were mixed in a screw-cap tube.

178 The chloroform was evaporated and $1 \mathrm{~mL}$ of $3 \mathrm{M}$ methanolic hydrochloric acid was

179 added to each tube. The mixture was bubbled with nitrogen to remove oxygen. The tubes

180 were heated at $78^{\circ} \mathrm{C}$ for 30 minutes to synthesize the methyl esters. To isolate the methyl

181 esters from water soluble compounds, $2 \mathrm{~mL}$ of water and $2 \mathrm{~mL}$ of hexane:chloroform 
$182(4: 1, \mathrm{v} / \mathrm{v})$ were added to the tubes and then shaken for 30 seconds and centrifuged for 2

183 minutes. The upper layer, containing methyl esters in hexane:chloroform, was pipetted to

184 a separate vial. This separation was repeated three times, each time adding more

185 hexane:chloroform to the remaining aqueous layer, with the methyl ester fraction

186 collected in a common vial. The organic layer was dried under nitrogen. The sample was

187 then dissolved in $100 \mu \mathrm{L}$ of hexane and transferred to gas chromatograph (GC) vials.

\section{$188 \quad$ 2.4. Analysis of lipids}

189 The GC-FID (Flame Ionization Detector) analysis was performed at the Kansas

190 Lipidomics Research Center with a 6890N GC (Agilent Technologies, Santa Clara, CA)

191 coupled to an FID. The GC was fitted with a HP-88 capillary column with a bis

192 (cyanopropyl) polysiloxane stationary phase (column length: $100 \mathrm{~m}$, internal diameter:

$193250 \mu \mathrm{m}$, film thickness: $0.25 \mu \mathrm{m}$ ). Helium was used as the carrier gas at a flow rate of 1.2

$194 \mathrm{~mL} \mathrm{~min}{ }^{-1}$. The injector port was maintained at $275^{\circ} \mathrm{C}$. An Agilent 7683 autosampler was

195 used to inject $1 \mu \mathrm{L}$ of the sample in the split mode with a split ratio of 10:1. The GC

196 temperature ramp was operated as follows, initial temperature of $70^{\circ} \mathrm{C}$, ramp 1 at $15^{\circ} \mathrm{C}$

$197 \min ^{-1}$ to $175^{\circ} \mathrm{C}$, ramp 2 at $1^{\circ} \mathrm{C} \min ^{-1}$ to a final temperature of $235^{\circ} \mathrm{C}$. The FID was

198 operated at $260^{\circ} \mathrm{C}$. The hydrogen flow to the detector was $30 \mathrm{~mL} \mathrm{~min}^{-1}$ and air flow was

$199400 \mathrm{~mL} \mathrm{~min}^{-1}$. The sampling rate of the FID was $20 \mathrm{~Hz}$. The data were processed using

200 Chemstation software.

201 3. Results and discussion

202 3.1. Results from literature review

203 The molar percentage of oleic, linoleic and linolenic acids were plotted versus the 204 temperature during the grain fill for each of the four crops are presented in Figures 2, 3, 
2054 , and 5, respectively. The dotted line represents the best linear fit (minimized residuals),

206 while the solid lines represent the 95\% confidence intervals based on the estimation of

207 the standard deviation. The slope and y-intercepts for each of the linear regressions and

208 their respective standard deviations were determined using SAS. SAS was also used to

209 confirm that the residuals were approximately normal and the use of a linear regression

210 was appropriate for the literature values collected.

211 In soybean, canola, and sunflower, as the temperature increased, the percentage of

212 oleic acid increases while the percentage of linoleic and linolenic acids decreased. These

213 results agree with other studies that were conducted in greenhouses over broad

214 temperature ranges with canola and sunflower $\left(12\right.$ to $\left.27^{\circ} \mathrm{C}\right)$ (Tremolieres et al., 1982)

215 and with studies performed in fields with soybean, canola, and sunflower over smaller

216 temperature ranges $\left(12\right.$ to $17^{\circ} \mathrm{C}$ ) (Werteker et al., 2010). Camelina was unique in that its

217 lipid profile was nearly independent of growing temperature over the range investigated.

218 Other authors have found that the effect of temperature on fatty acid composition was

219 small for nine varieties of camelina, although they noted that during a particularly warm

220 year the different varieties produced 2\% less linolenic acid than the same varieties during

221 a normal year (Crowley and Frohlich, 1998). Soybean and sunflower exhibited the

222 strongest trends towards more monounsaturated and less polyunsaturated fatty acids with

223 increasing temperature while canola and camelina changed minimally with increasing

224 temperature. Camelina has not been extensively studied and had fewer data points over a

225 smaller temperature range than the other crops. The data collected had temperatures

226 during the grain fill between $19^{\circ} \mathrm{C}$ and $28^{\circ} \mathrm{C}$. This is a relatively small range compared

227 with the other three crops studied which had data from approximately $10^{\circ} \mathrm{C}$ to $40^{\circ} \mathrm{C}$. 
228 More work needs to be completed, with camelina grown in both cooler and warmer

229 temperatures to gain a more complete understanding of the effect of temperature during

230 the grain fill on the molar amounts of lipids present.

\section{$231 \quad$ 3.2. Field studies}

232 For oilseeds grown near Manhattan, KS, the oil profiles varied considerably

233 between crops (Table 2). The oil profiles varied considerably between crops. Oleic acid

234 was the primary fatty acid in canola and sunflower seeds. The soybean varieties had far

235 more linoleic acid than oleic or linolenic acid. Camelina was highly unsaturated, having

236 the most linolenic acid of any of the oil seeds grown. Camelina was the only crop with

237 significant amounts of fatty acids with 20 carbons.

238 To compare percentage of fatty acid predicted by the regression to the

239 experimentally determined percentage of fatty acid contained in the seed, the temperature

240 during the grain fill must be known. The temperature during the grain fill for the

241 Manhattan, KS crops were calculated based on the growing season temperatures (Table

242 3). The experimentally determined molar percentages of the crops were compared to the

243 predicted value of the molar percentage of lipids from the regressions (Figure 6). Points

244 closest to the diagonal line represent an agreement between the lipid profile determined

245 from the plants grown in Manhattan, KS and the value predicted by the correlation from

246 the literature values. For soybean, canola and camelina, the developed correlations

247 accurately predicted the molar percentage of lipids within the confidence intervals. The

248 sunflower regression under predicted the amount of oleic acid and over predicted the

249 amount of linoleic acid. Sunflower was the only plant that did not contain linolenic acid.

250 The planted sunflower hybrid was classified as mid-oleic or having between 55 and $75 \%$ 
251 oleic acid, but the grain from this trial, grown under high temperatures, had $77 \%$ oleic

252 acid. This was perhaps due to high temperatures increasing the oleic seed content above

253 typical levels. The discrepancy between the experimentally determined amount of lipids

254 and the values predicted by the regressions might have resulted because the literature

255 review purposefully excluded studies with oleic acid outside the mid-oleic range in an

256 attempt to control for genetic differences. Differences could also be explained by other

257 factors which are known to affect the fatty acid profile such as precipitation or genotype

258 (Rao et al., 1998; Gao et al., 2009). Some literature suggests that agricultural practices

259 can also affect oil profiles (Vera et al., 2007).

260 Enzymes that promote the formation of lipids are similar in all higher plants but

261 temperature affects lipid profiles to different degrees. Previous research documents that

262 the lipid profiles of all four studied crops are affected by temperature and the amount of

263 oleic acid increases while the amount of linoleic and linolenic acids decrease with

264 increasing temperature (Tremolieres et al., 1982; Wolf et al., 1982; Lajara et al., 1990;

265 Zubr and Mattha, 2002). There are two accepted explanations for how temperature causes

266 changes in the lipid profile. The earliest literature suggests that oilseeds produce more

267 linoleic acid at lower temperatures because oxygen is a necessary reactant for desaturase

268 enzyme activity and oxygen is more soluble in water at lower temperatures (Harris and

269 James, 1969). Later literature confirmed that the activity of oleoyl-phosphatidylcholine

270 desaturase, an important enzyme in the desaturation of oleic acid into linoleic acid, is

271 highly dependent on the amount of available oxygen in sunflowers (Rolletschek et al.,

272 2007). It has also been suggested that higher temperatures directly affect the lipid profile

273 by destabilizing the enzyme (Martinez-Rivas et al., 2003). 


\section{4. Conclusions}

275 The lipid profile of a crop determines its ability to be used in industrial and

276 nutritional applications. The linear regressions from previously published results suggest

277 that the molar percentage of oleic, linoleic and linolenic acids contained in soybean,

278 canola, and sunflower depend on the temperature during grain fill. The molar amounts of

279 oleic, linoleic and linolenic acids in the soybean, canola, and camelina crops grown in

280 Manhattan, KS were within the 95\% confidence interval of each of their respective

281 regressions. Higher temperatures will result in lower amounts of polyunsaturated lipids

282 and higher amounts of monounsaturated lipids in soybean, canola, and sunflower. As

283 average temperatures across the planet rise, oilseed crops are going to produce more

284 monounsaturated fats and less polyunsaturated fats.

286 The lipid analyses described in this work were performed at the Kansas Lipidomics

287 Research Center Analytical Laboratory. Instrument acquisition at the Kansas Lipidomics

288 Research Center was supported by National Science Foundation (EPS 0236913, DBI

289 0521587), Kansas Technology Enterprise Corporation, K-IDeA Networks of Biomedical

290 Research Excellence (INBRE) of National Institute of Health (P20RR16475), and Kansas

291 State University.

292 This work was partially supported by the Functional Genomics Consortium, an initiative

293 of the Targeted Excellence Program of Kansas State University.

294 This material is based upon work supported by National Science Foundation Grant: From

295 Crops to Commuting: Integrating the Social, Technological, and Agricultural Aspects of

296 Renewable and Sustainable Biorefining (I-STAR); NSF Award No.: DGE-0903701. 
297 Acknowledgements: The authors would like to acknowledge Mary Roth, Ruth Welti, 298 Oliver Freeman and Bandiogou Diawara for their help.

299

300 
301 Aksouh, N.M., Jacobs, B.C., Stoddard, F.L., Mailer, R.J., 2001. Response of canola to

302 different heat stresses. Aust. J. Agric. Res. 52, 817-824.

303 Aksouh-Harradj, N.M., Campbell, L.C., Mailer, R.J., 2006. Canola response to high and

304 moderately high temperature. Can. J . Plant Sci. 86, 967-980.

305 Angelini, L., Moscheni, E., Colonna, G., Belloni, P., Bonari, E., 1997. Variation in

306 agronomic characteristics and seed oil composition of new oilseed crops in central

$307 \quad$ Italy. Ind. Crop. Prod. 6, 313-323.

308 Bhardwaj, H.L., Hamama, A.A., 2008. Oil quality of winter hardy rapeseed germplasm

309 relative to biodiesel production. World J. Agric. Sci. 4, 1-6.

310 Budin, J.T., Breene, W.M., Putnam, D.H., 1995. Some compositional properties of

311 camelina. J. Am. Oil Chem. Soc. 72, 309-315.

312 Canvin, T., 1965. The effect of temperature on the oil content and fatty acid composition

313 of the oils from several oil seed crops. Can. J. Bot. 43, 63-69.

314 Crowley, J.G., Frohlich, A., 1998. Factors affecting the composition and use of camelina.

315 Crop Research Center, Oak Park, Carlow.

316 Downey, R.K., 1990. Canola: A quality brassica oilseed, in: Janick, J., Simon, J.E. (Eds.),

317 Advances in New Crops. Timber Press, Portland, OR, pp. 211-217.

318 Economic Research Service, USDA. “Table 20: Sunflowerseed: Acreage planted,

319 harvested, yield, production and value, U.S., 1980-2011” [WWW Document], n.d.

320 Oil Crops Yearbook. Last modified March 2012. URL

321 http://usda.mannlib.cornell.edu/MannUsda/viewDocumentInfo.do?documentID=129

3220.


323 Gao, J., Hao, X., Thelen, K.D., Robertson, G.P., 2009. Agronomic Management System

324 and Precipitation Effects on Soybean Oil and Fatty Acid Profiles. Crop Sci. 49,

3251049.

326 Grompone, M.A., 2005. Sunflower Oil, in: Bailey’s Industrial Oil and Fat Products. John $327 \quad$ Wiley \& Sons, Inc., pp. 655-730.

328 Gugel, R.K., Falk, K.C., 2006. Agronomic and seed quality evaluation of Camelina sativa 329 in western Canada. Can. J . Plant Sci. 2, 1047-1059.

330 Harris, H., McWilliam, J.R., Mason, W.K., 1978. Influence of temperature on oil content 331 and composition of sunflower seed. Aust. J. Agric. Res. 29, 1203-1212.

332 Harris, P., James, A.T., 1969. The effect of low temperatures on fatty acid biosynthesis in 333 plants. Biochem. J. 112, 325-330.

334 Iqbal, M.C.M., Weerakoon, S.R., Geethanjalie, H.D.N., Peiris, P.K.D., Weerasena, 335 O.V.D.S.J., 2011. Changes in the fatty acids in seeds of interspecific hybrids 336 between Brassica napus and Brassica juncea. Crop Pasture Sci. 62, 390-395.

337 Kim, D., Jeannotte, R., Welti, R., Bockus, W.W., 2013. Lipid profiles in wheat cultivars

338 resistant and susceptible to tan spot and the effect of disease on the profiles. 339 Phytopathol. 103, 74-80.

340 Lajara, J.R., Diaz, U., Quidiello, F.D., 1990. Definite influence of location and climatic 341 conditions on the fatty acid composition of sunflower seed oil. J. Am. Oil Chem. $342 \quad$ Soc. $67,618-623$.

343 Larson, T.R., Edgell, T., Byrne, J., Dehesh, K., Graham, I. a, 2002. Acyl CoA profiles of 344 transgenic plants that accumulate medium-chain fatty acids indicate inefficient 345 storage lipid synthesis in developing oilseeds. Plant J: Cell Mol. Biol. 32, 519-27. 
346 Lu, C., Kang, J., 2008. Generation of transgenic plants of a potential oilseed crop

347 Camelina sativa by Agrobacterium-mediated transformation. Plant. Cell Rep. 27, $348 \quad 273-8$.

349 Maestri, M., Labuckas, D.O., Meriles, M., Lamarque, A.L., Zygadlo, J.A., Guzma, C.A., 350 1998. Seed Composition of Soybean Cultivars Evaluated in Different Environmental 351 Regions. J. Sci. Food Agric. 494, 494-498.

352 Martinez-Rivas, J.M., Sanchez-Garcia, A., Dolores Sicardo, M., Teresa Garcia-Diaz, M., 353 Mancha, M., 2003. Oxygen-independent temperature regulation of the microsomal 354 oleate desaturase (FAD2) activity in developing sunflower (Helianthus annuus ) 355 seeds. In Vitr. 179-185.

356 Martınez-Force, E., Alvarez-Ortega, R., Cantisan, S., Garces, R., 1998. Fatty acid 357 composition in developing high saturated sunflower (Helianthus annuus) seeds:

358 Maturation changes and temperature effect. J. Agric. Food Chem. 46, 3577-3582.

359 Metzger, J.O., Bornscheuer, U., 2006. Lipids as renewable resources: current state of 360 chemical and biotechnological conversion and diversification. Appl. Microbiol. $361 \quad$ Biotech. 71, 13-22.

362 Monyem, A., Gerpen, J., 2001. The effect of biodiesel oxidation on engine performance 363 and emissions. Biomass Bioenergy 20, 317-325.

364 Nagao, A., Yamazaki, M., 1983. Lipid of sunflower seeds produced in Japan. J. Am. Oil $365 \quad$ Chem. Soc. 60, 1654-1658.

366 Putnam, D.H., Budin, J.T., Field, L.A., Breene, W.M., 1991. New Crops: Exploration, 367 Research, and Commericialization, 2nd ed. John Wiley, New York. 
368 Rao, M.S., Bhagsari, A.S., Mohamed, A.I., 1998. Yield, protein, and oil quality of

369 soybean genotypes selected for tofu production. Plant Foods Hum. Nutr. 52, 241-51.

370 Ren, C., Bilyeu, K.D., Beuselinck, P.R., 2009. Composition, Vigor, and Proteome of

371 Mature Soybean Seeds Developed under High Temperature. Crop Sci. 49, 1010.

372 Rennie, B.D., Tanner, J.W., 1989. Fatty acid composition of oil from soybean seeds

373 grown at extreme temperatures. J. Am. Oil Chem. Soc. 66, 1622-1624.

374 Robertson, J.A., Thomas, J.K., Burdick, D., 1971. Chemical composition of the seed of

375 sunflower hybrids and open pollinated varieties. J. Food Sci. 36, 873-876.

376 Rolletschek, H., Borisjuk, L., Sánchez-García, A., Gotor, C., Romero, L.C., Martínez-

377 Rivas, J.M., Mancha, M., 2007. Temperature-dependent endogenous oxygen

378 concentration regulates microsomal oleate desaturase in developing sunflower seeds.

379 J. Exp. Bot. 58, 3171-81.

380 SAS Version 8. SAS Institute Inc., 2006. .

381 Shafiullah, Rana, M.A., Yousaf, M., Mohmand, A.S., Ali, G.M., 1994. Effect of different

382 planting dates on yield and yield components of sunflower (Helianthus annuus L.).

383 Crop Res. 8, 199-206.

384 Singh, D., Pfromm, P.H., Rezac, M.E., 2011. Overcoming Mass-Transfer Limitations in

385 Partial Hydrogenation of Soybean Oil Using Metal-Decorated Polymeric

$386 \quad$ Membranes. AIChE J. 57.

387 Singh, D., Rezac, M.E., Pfromm, P.H., 2009. Partial Hydrogenation of Soybean Oil with

388 Minimal Trans Fat ... J. Am. Oil Chem. Soc. 86, 93-101. 
Singh, D., Rezac, M.E., Pfromm, P.H., 2010. Partial hydrogenation of soybean oil using metal-decorated integral-asymmetric polymer membranes: Effects of morphology and membrane properties. J. Mem. Sci. 348, 99-108.

Tremolieres, A., Dubacq, J.P., Drapier, D., 1982. Unsaturated fatty acids in maturing seeds of sunflower and rape - Regulation by temperature and light-intensity. Phytochem. 21, 41-45.

Unger, P., Thompson, T., 1982. Planting date effects on sunflower head and seed development. Agron. J. 74, 389-395.

Vantoai, T.T., Lee, J., Goulart, P.F.P., Shannon, J.G., Alves, J.D., Nguyen, H.T., Yu, O., Rahman, M., Islam, R., 2012. Soybean (Glycine max L. Merr.) seed composition response to soil flooding stress. J. Food Agric. Env. 10, 795-804.

Vera, C.L., Downey, R.K., Woods, S.M., Raney, J.P., Mcgregor, D.I., Elliott, R.H., Johnson, E.N., 2007. Yield and quality of canola seed as affected by stage of maturity at swathing. Can. J . Plant Sci. 13-26.

Werteker, M., Lorenz, A., Johannes, H., Berghofer, E., Findlay, C.S., 2010.

Environmental and Varietal Influences on the Fatty Acid Composition of Rapeseed, Soybeans and Sunflowers. J. Agron. Crop Sci. 196, 20-27.

Wolf, R.B., Cavins, J.F., Kleiman, R., Black, L.T., 1982. Effect of temperature on soybean seed constituents: Oil, protein, moisture, fatty acids, amino acids and sugars. J. Am. Oil Chem. Soc. 59, 230-232.

Zubr, J., Mattha, B., 2002. Effects of growth conditions on fatty acids and tocopherols in Camelina sativa oil. Ind. Crop. Prod. 15, 155-162. 
412 Figure 1: The procedure for extraction and separation of triglycerides from seed proteins,

413 synthesis of methyl esters, and subsequent separation from water-soluble organics from

414 oilseed crops grown for analysis by GC.

415

416 Figure 2: Linear regressions of the molar amount of the three most common lipids in

417 soybean gathered the literature plotted versus the mean high temperature during the grain

418 fill. See Table 1 for references. a) oleic acid b) linoleic acid c) linolenic acid

420 Figure 3: Linear regressions of the molar amount of the three most common lipids in

421 canola gathered the literature plotted versus the mean high temperature during the grain

422 fill. See Table 1 for references. a) oleic acid b) linoleic acid c) linolenic acid

424 Figure 4: Linear regressions of the molar amount of the three most common lipids in 425 camelina gathered the literature plotted versus the mean high temperature during the 426 grain fill. See Table 1 for references. a) oleic acid b) linoleic acid c) linolenic acid 427

428 Figure 5: Linear regressions of the molar amount of the two most common lipids in 429 sunflower gathered the literature plotted versus the mean high temperature during the 430 grain fill. See Table 1 for references. a) oleic acid b) linoleic acid

432 Figure 6: Comparison of predicted values from linear regression of literature values 433 versus data from crops grown in Manhattan, KS. The error bars in the $\mathrm{x}$ and $\mathrm{y}$-direction 434 are the 95\% confidence intervals for the 20 samples collected for each lipid for each crop 
435 grown in Manhattan, KS and for the values collected from the literature, respectively. a)

436 oleic acid b) linoleic acid c) linolenic acid. 
438 Table 1: Published data included in this study.

\begin{tabular}{|c|c|c|}
\hline Citation (Author, Year) & Location & Plants Grown \\
\hline (Aksouh et al., 2001) & Greenhouse & Canola \\
\hline (Aksouh-Harradj et al., 2006) & Greenhouse & Canola \\
\hline (Angelini et al., 1997) & Central Italy & Camelina \\
\hline (Bhardwaj and Hamama, 2008) & Virginia & Canola \\
\hline (Budin et al., 1995) & Minnesota & Camelina \\
\hline (Canvin, 1965) & Greenhouse & Sunflower \\
\hline (Gao et al., 2009) & Michigan & Soybean \\
\hline (Gugel and Falk, 2006) & $\begin{array}{l}\text { Saskatoon and Scott, Saskatchewan } \\
\text { and Beaverlodge, Alberta }\end{array}$ & Camelina \\
\hline (Iqbal et al., 2011) & Greenhouse & Canola \\
\hline (Larson et al., 2002) & Gnhouse & Canola \\
\hline (Lu and Kang, 2008) & Greenhouse & Camelina \\
\hline (Maestri et al., 1998) & Cordoba, Argentina & Soybean \\
\hline (Martınez-Force et al., 1998) & Greenhouse & Sunflower \\
\hline (Nagao and Yamazaki, 1983) & Okayama, Japan & Sunflower \\
\hline (Putnam et al., 1991) & Rosemount, MN & Soybean, Canola, Camelina \\
\hline (Rao et al., 1998) & Fort Valley, GA & Soybean \\
\hline (Ren et al., 2009) & Greenhouse & Soybean \\
\hline (Rennie and Tanner, 1989) & Greenhouse & Soybean \\
\hline (Robertson et al., 1971) & $\begin{array}{l}\text { Tifton, GA, Baton Rouge, LA, } \\
\text { College Station, TX }\end{array}$ & Sunflower \\
\hline (Shafiullah et al., 1994) & Islamabad, Pakistan & Sunflower \\
\hline (Tremolieres et al., 1982) & Greenhouse & Canola and Sunflower \\
\hline (Unger and Thompson, 1982) & Bushland, TX & Sunflower \\
\hline (Vantoai et al., 2012) & Columbia and Portageville, MO & Soybean \\
\hline (Wolf et al., 1982) & Greenhouse & Soybean \\
\hline (Zubr and Mattha, 2002) & $\begin{array}{l}\text { Mullhein, Paderborn, Carlow, } \\
\text { Germany and Uppsala, Sweden }\end{array}$ & Camelina \\
\hline
\end{tabular}


439 Table 2: Lipids contained in four oilseed crops grown in Manhattan, KS in 2011 listed as average of twenty samples.

\begin{tabular}{|c|c|c|c|c|c|c|c|c|c|c|}
\hline \multicolumn{11}{|c|}{ Lipid (mol of lipid/total mol of identified lipids) } \\
\hline Crop & $\begin{array}{c}\text { C16:0 } \\
\text { Palmitic }\end{array}$ & $\begin{array}{l}\text { C18:0 } \\
\text { Stearic }\end{array}$ & $\begin{array}{l}\text { C18:1 } \\
\text { Oleic }\end{array}$ & $\begin{array}{c}\text { C18:2 } \\
\text { Linoleic }\end{array}$ & $\begin{array}{c}\text { C18:3 } \\
\text { Linolenic }\end{array}$ & $\begin{array}{c}\text { C20:1 } \\
\text { Eicosenoic }\end{array}$ & $\begin{array}{c}\text { C20:2 } \\
\text { Eicosadienoic }\end{array}$ & $\begin{array}{c}\text { C20:3 } \\
\text { Eicosatrienoic }\end{array}$ & Sum & $\begin{array}{c}\text { Harvest } \\
\text { Date }\end{array}$ \\
\hline Soybean & $11 \pm 0.5$ & $4 \pm 0.5$ & $22 \pm 1.1$ & $55 \pm 1.8$ & $8 \pm 0.5$ & $<1$ & ND & ND & 100 & Sept 20 \\
\hline Canola & $6 \pm 0.7$ & $2 \pm 0.2$ & $62 \pm 1.0$ & $22 \pm 0.5$ & $6 \pm 0.2$ & $1 \pm 0.1$ & $<1$ & ND & 100 & July 9 \\
\hline Camelina & $7 \pm 0.9$ & $2 \pm 0.4$ & $17 \pm 1.9$ & $21 \pm 2.4$ & $31 \pm 3.4$ & $13 \pm 0.6$ & $2 \pm 0.7$ & $1 \pm 0.1$ & $94 \dagger$ & June 29 \\
\hline Sunflower & $6 \pm 0.5$ & $3 \pm 0.3$ & $77 \pm 4.8$ & $14 \pm 4.8$ & ND & $<1$ & ND & ND & 100 & Aug 25 \\
\hline
\end{tabular}

440 ND: Not detected

$441+$ The molar percentages for camelina do not sum to 100 because camelina also produced C18:3n6 and C20:0 fatty acids ( 3\%) and

442 detectable amounts of C22:0, C20:3n6, C22:2, C24:0 and C24:1 fatty acids. 
444 Table 3: Monthly temperature for Manhattan, Kansas

\begin{tabular}{ccc}
\hline & \multicolumn{2}{c}{ Monthly average high temperature $\left({ }^{\circ} \mathrm{C}\right)$} \\
\cline { 2 - 3 } Month & 2011 & 30 year average \\
\hline March & 12.3 & 14.5 \\
April & 19.6 & 20.3 \\
May & 23.6 & 25.1 \\
June & 31.2 & 30.6 \\
July & 36.7 & 33.3 \\
August & 33.6 & 31.6 \\
September & 26.8 & 26.4 \\
\hline
\end{tabular}

445 